\title{
Witnessing Trauma through Discordant Chronology of Words in Yvonne Vera's Under the Tongue
}

\author{
*SHAMAILA DODHY ${ }^{1,2}$ \\ HARDEV KAUR ${ }^{2}$ \\ ${ }^{1}$ Department of English, University of the Punjab, Lahore, Pakistan \\ ${ }^{2}$ Department of English, Faculty of Modern Languages and Communication, \\ Universiti Putra Malaysia, 43400 Serdang, Selangor, Malaysia \\ *Corresponding author: shamaila.english@pu.edu.pk
}

Published online: 26 September 2018

To cite this article: Dodhy, S. and Kaur, H. 2018. Witnessing trauma through discordant chronology of words in Yvonne Vera's Under the Tongue. KEMANUSIAAN the Asian Journal of Humanities 25(2): 73-89, https://doi.org/10.21315/kajh2018.25.2.4

To link to this article: https://doi.org/10.21315/kajh2018.25.2.4

\begin{abstract}
Yvonne Vera is a reformist writer of Zimbabwe who agitated the society to attend to serious issues in the life of a Zimbabwean woman. This paper will examine Yvonne Vera's Under the Tongue in which representations of language of monologue contribute to the creation of an atmosphere in which the pain of female body is obviously felt. The legacies of colonialism and strategic policies of nationalism collaborate to facilitate the vulnerability of women thus contributing to their violation of rights and victimisation. It is a metaphorical representation of female resistance against violent male Zimbabwean society. The trauma of the victim is thoughtfully integrated into linguistic and symbolic systems aesthetically created by the writer. Using the discordant chronology of words of the female protagonist, Vera stylistically identifies the silence of a girl who is captive of flashbacks and intrusive thoughts but struggles to liberate herself from the discourse of pain. Restoration of confidence does take place with the power of language. By articulating a private experience of a victimised young girl, the writer reclaims the essential power of women's speech and silences in the context of gendered nationalist ideology where sacrifices of women have been reduced to an invisible state by historiographers.
\end{abstract}

Keywords and phrases: narrative, pain, silence, trauma, voice

\section{Introduction to Trauma Studies}

Trauma studies have taken the concept of trauma from the field of psychiatry and linked it to the discipline of literature, the two worlds which are often falsely divided; one is related to mental health and the other to the realm of imagination. It is the study of fiction and trauma which proves that trauma is not opposed to 
the real world, instead inextricably associated to real life. Literary works depict not only the private trauma of an individual but also elucidate social reasons which become the cause of abuse, thus offer a broad spectrum by turning the camera inside and presenting societal critique also. The narratives of trauma are also concerned with the issues of gender-politics, race and society. This results in "trauma fiction" performing an ethical function as it investigates the causes for and the consequences of a particular traumatic experience.

The study of psychological trauma has become a contemporary condition because the struggle to conceptualise it is becoming increasingly visible in a world where the international media wants to cover indigenous and worldwide conflicts, so these experiences of psychological traumatisation are witnessed by people far removed from the actual site of the event. The international media daily delivers messages that horrific incidents happen to a wide range of people, casting long-term effects on survivors of such happenstances. With the world becoming a global village by the use of advanced technology in communication, there is an increased visibility of many types of violations that cause trauma resulting from war, terrorism and natural catastrophes in addition to personal traumata like abuse and accidents. It is essential to recognise "the urgency of learning more about the traumatic reaction to violent events and about the means of helping to alleviate suffering" (Caruth 1995, vii) because trauma results in severe outcomes in the lives of those who are tormented by it. There has been an ongoing power struggle especially in the representation and treatment of traumatic experiences related to women. The afflicted women are silenced through oppression and marginalisation which results in turning them voiceless. In a state of voicelessness, it becomes challenging to express the psychological trauma which by its nature is "unspeakable" narrative of the victim. People like Anne Whitehead believe that "the more experimental forms emerging out of postmodernist and postcolonial fiction offer the contemporary novelist a promising vehicle for communicating the unreality of trauma, while still remaining faithful to the facts of history" $(2004,87)$. In fact, she points out the origin of a newly developing genre which she terms "trauma fiction" in two theoretical movements - postmodernism and postcolonialism - together with "a postwar legacy or consciousness" $(2004,81)$ such as "intertextuality, repetition and a dispersed or fragmented narrative voice" (84). So it is the representation of trauma that compels writers, who represent traumatic knowledge, to emphasise that this psychological agony can only be conveyed through a mark of disorientation.

A contemporary theorist of trauma, Cathy Caruth, in Trauma: Explorations in Memory defines trauma as: 
A response, sometimes delayed, to an overwhelming event or events, which takes the form of repeated, intrusive hallucinations, dreams, thoughts or behaviors stemming from the event, along with numbing that may have begun during or after the experience, and possibly also increased arousal to (and avoidance of) stimuli recalling the event $(1995,4)$.

According to Caruth, the definition of trauma leaves out the fact that pathology cannot be defined by the traumatic event itself, since it may or may not be catastrophic, and may not traumatise everyone equally; and it also cannot be defined as a "distortion" of that event, because it achieves its haunting power as a result of distorting personal significances attached to it (Caruth 1995, 4). Hence, the event itself does not cause the same trauma in everybody who experiences it. Consequently, Caruth states, "The pathology consists, rather, solely in the structure of its experience or reception: the event is not assimilated or experienced fully at the time, but only belatedly, in its repeated possession of the one who experiences it" [emphasis in original] $(1995,4)$. Caruth thus stresses, as earlier Sigmund Freud did, that the traumatic event is so overwhelming that the mind cannot integrate it at the time of its occurrence, which then leads to belated return of the trauma in literal re-experiences such as flashbacks and nightmares. The event is experienced, later in life, in breaks and breaches which is extremely agonizing and beyond human comprehension. The victim has not experienced the event as it happened and therefore remains unavailable to willful recall. This results in disorienting the victim's sense of wholeness because the mind tries to recognise the event that was never consciously experienced. Even time seems to break down for the victim because "the traumatic memory persists in a half-life, rather like a ghost, a haunting absent presence of another time in our time" (Luckhurst 2008, 81). So the past refuses to go back in time causing the victim to re-experience the pain repeatedly. Caruth also agrees with Freud's theory that the breach in the protective shield is caused by the individual's lack of preparedness for the shocking event. In Unclaimed Experience, Caruth draws a connection between Freudian trauma and its significance in literary theory. In the beginning, Caruth discusses a symbolic poem previously discussed by Freud to explain the concept of trauma. In Tasso's epic, Tancred, its hero accidentally kills his love, only to find himself repeating the same action of stabbing a tree, which speaks to him in the voice of his lost love, thereby not reconciling with the initial traumatic event. Caruth explains: "The actions of Tancred, wounding his beloved in a battle and then, unknowingly, seemingly by chance, wounding her again, evocatively represent in Freud's text the way that the experience of a trauma repeats itself, exactly and unremittingly, through the unknowing acts of the survivor and against his or her very will" (Caruth 1996, 2). She claims: 
The fact that the threat is recognized as such by the mind one moment too late. The shock of the mind's relation to the threat of death is thus not the direct experience of the threat, but precisely the missing of this experience, the fact that, not being experienced in time, it has not yet been fully known" (1996, 62; emphasis in original).

Freud's commitment to the concept is somewhat characterised by his bafflement, so he re-explored this idea in his essay "Beyond the Pleasure Principle" (2015; original work published in 1920). Traumatic nightmares do not fit with his understanding of dreams as wish fulfillments. He was perplexed by observing the condition of soldiers who, upon returning from the battlefield, display symptoms of what came to be known as "shell shock". He concluded that the obsessive return to the scene of horrors, what he called repetition compulsion, is in fact an attempt to imbibe the event retrospectively. After studying the mental instability of soldiers of the First World War, Freud explains, "A condition has long been known and described which occurs after severe mechanical concussions, railway disasters and other accidents involving a risk to life; it has been given the name of 'traumatic neurosis"' $(2015,12)$. After doing detailed analysis of the experiences of the patients, Freud concludes that the psychological state of these patients do not fit in the concept of "hysteria" which is often associated with these patients. More specifically, Freud claims that what makes trauma different is that "the chief weight in their causation seems to rest upon the factor of surprise, of fright" (2015, 12), which he explains is "the state a person gets into when he has run into danger without being prepared for it; it emphasizes the factor of surprise" (ibid.). It is because of surprise that the mind is unable to immediately process what happens during the traumatic event which the psyche must learn to incorporate at a later time. So in the field of trauma studies, Freud is the one who introduced the idea that trauma is a dialectical process - that the original event is neither incorporated completely by the consciousness, nor by the memory that later generates that experience.

This Freudian concept of trauma, and its history, is explored further by a psychiatrist, Judith Herman. In her influential text Trauma and Recovery: The Aftermath of Violence-From Domestic Abuse to Political Terror (1992), she opens the second chapter of the book by saying that psychological trauma is an affliction of the powerless. In addition, Herman highlights that before 1970 people ignored the fact that violence is a repetitive feature of women's domestic life. The reality of women's life is kept hidden under the cover, considering it a private truth. She vividly says, "to speak about experiences in sexual or domestic life was to invite public humiliation, ridicule, and disbelief. Women were silenced by fear and shame, and the silence of women gave license to every form of sexual 
and domestic exploitation" (Herman 1992, 28). Tracing the history of "the sex war", she says that though there is democracy in public life but in homes women are living in a primitive autocratic environment. Women should be conscious of the fact that they should "overcome the barriers of denial, secrecy, and shame that prevented them from naming their injuries" $(1992,29)$. This feminist awareness empowered victims to cross the barriers of privacy by supporting one another and taking collective action. It is in the decade of 1970s that women established the fact that rape is an atrocity and a crime of violence. It is a type of controlling and subordinating women through terror. It is recognised as a life-threatening event because mostly the victim is threatened of mutilation and death by the perpetrator. The after-effects of rape are long-lasting as "victims complained of insomnia, nausea, startle responses, and nightmares, as well as dissociative or numbing symptoms" $(1992,31)$. The initial focus of the investigation by women of $70 \mathrm{~s}$ was the assault by strangers called "street rape" which led to the investigation of "acquaintance rape, date rape, and rape in marriage" $(1992,31)$. This exposed other forms of violence like domestic battery and varied types of private coercion. From the rape of adults, the study moved on to the analysis of abuse against children. Herman draws an interesting comparison between the affectees of rape, domestic battery and incest with the survivors of war. She says that just as war veterans have horrifying repercussions similarly these women also suffer immensely afterwards, so one can say that there is a continuous war going on at homes which she calls the sex war and the casualties of this war are "rape victims, battered women, and sexually abused children" $(1992,32)$.

Criticising the manual of the American Psychiatrist Association, which describes the traumatic event as outside the range of human experience, Herman says that rape, battery and other forms of domestic violence are so common that one cannot say that traumatic events are outside the range of human experience. The victims of trauma are slow to react because they are so overwhelmed by the experience. The system of self-defense becomes disorganised. These "traumatic events produce profound and lasting changes in physiological arousal, emotion, cognition, and memory. ... The traumatized person may experience intense emotion but without clear memory of the event, or may remember everything in detail but without emotion" (Herman 1992, 34). Without knowing the causes, the victim might find herself in a state of vigilance which increases the irritability within her. The symptoms of trauma become disconnected and establish their independent existence. This fragmentation destroys the system of self-protection which is inherently present in human beings.

The symptoms of trauma fall in three categories called hyperarousal, intrusion and constriction. "Hyperarousal reflects the persistent expectation of danger; 
intrusion reflects the indelible imprint of the traumatic moment; constriction reflects the numbing response of surrender" (Herman 1992, 35). When the body is injured or invaded, the autonomy of the person is violated "at the level of basic bodily integrity" (Herman 1992, 52-53). The victim often loses control over the functions of the body which is the most humiliating feature of trauma. Crucial to Herman's work is her assertion on the essential stages of recovery for the trauma victim. She thinks that "remembering and telling the truth about terrible events are prerequisites both for the restoration of the social order and for the healing of individual victims" $(1992,1)$. For Herman, the process of healing trauma in a victim involves "reconstructing the trauma story, and restoring the connection between survivors and their community ... challenge us to reconnect the fragments, to reconstruct history, to make meaning of their present symptoms in the light of past events" $(1992,3)$.

Both Freud and Caruth used literary metaphors to identify and clarify the concept of trauma. The term trauma fiction, somehow, appears contradictory to Anne Whitehead because the traumatic event is so overwhelming that it resists language while fiction is narration of the events. This has given rise to a new style of writing to preserve the historical records of collective trauma like slavery and colonialism plus individual trauma which is mostly borne by women at domestic level. For this, "novelists have frequently found that the impact of trauma can only be adequately be represented by mimicking its forms and symptoms, so that temporality and chronology collapse, and narratives are characterised by repetition and indirection" (Whitehead 2004, 3). For Whitehead, quite like Roger Luckhurst, the "ghost" is the most appropriate embodiment of "disjunction of temporality, the surfacing of the past in the present" $(2004,6)$. This is one of the reasons that many novels are being written to explore haunted histories. Many deal with the issues of those people who have not been able to reconcile with the horrors of the past or with the ghost of a person who died too suddenly and unexpectedly. Like Luckhurst, she also gives the example of Toni Morrison's Beloved because it deals with Seth who is haunted by the ghost of her daughter whom she herself has murdered in fear of slavery, the daughter returns back to mother to claim her love which has been denied to her. The novel also presents "the unresolved trauma of slavery" (Whitehead 2004, 6) which disturbs almost all the characters as the horrors of slavery are so over-whelming that they fail to accept the fact that now they free are and are no more a part of bonded labour. This is what Caruth has called "crisis of truth" (Caruth 1995, 7) and this crisis functions beyond the level of individual to mark the ways in which the historical experience can be analysed at cultural level. She lays emphasis on the responsibility of the listener who has to respond to the testimony with a collaborative relationship and at the same time has to maintain a distance to avoid appropriation. A subtle balance has to be maintained between 
witnessing the testimony and respect for the experience of other with a reasonable distance. She discusses the politics of place, there is a relation between trauma and place as the survivors live among pieces of memory scattered across landscape. The landscape helps in "rescuing and redeeming the stories of the conquered and the dispossessed" (Whitehead 2004, 10) the past. It sometimes becomes a redemptive counterforce to the catastrophe. These sites of memory, cultural and geographical locations, become significant redeeming forces. She has drawn attention to those writers who have "mimicked [trauma's] symptomology at a formal level" (2004, 161) through "repetition, indirection and the dispersal of narrative voice in works of trauma fiction" (ibid.). Whitehead considers that trauma has a contradictory nature because it resists narration and at the same time the sufferer wants to share his experience. This corresponds to the literary distinction between theme and style of a literary work. She has suggested that "trauma, like fiction, occupies an uncertain, but nevertheless productive, site or place between content and form" $(2004,162)$.

The Trauma Question (2008) by Roger Luckhurst brings in focus on the process of modernisation of the society which has increased the risk factor in the life of a contemporary man. The modernisation has not decreased problems in humanlife; instead it has resulted in "over-population, technological saturation, pollution, and over-dependency on complex technological ensembles" (212) which generate greater risks in human life. On the other hand, since 1990s global conflicts have increased, just the "American occupation of Iraq has killed an estimated 77,000 civilians, produced two million refugees and another two million internally displaced persons" (ibid.). That is why much work is being done to solve the trauma question which,

Seeks to work through the traumatic past, premising communality not on preserving trauma but on transforming its legacy. This is an attempt to transform Freud's distinctions between remembering, repeating and working in 1914 into a model for cultural or political critique. This is perhaps why Toni Morrison's Beloved remains such an important text: the melancholic ghost continues to haunt, but the other daughter, Denver, is allowed to start to refashion some other kind of community afterwards (Luckhurst 2008, 213).

The reality of post-traumatic reaction and the struggle of professional psychologists to abolish them cannot be denied. This spirit of investigation reaffirms that trauma is a "complex knot that binds together multiple strands of knowledge and which can be best understood through plural, multidisciplinary perspectives" $(2008,214)$. 
Under the Tongue (1996) has many notions of Freudian trauma theory overlapping with the characteristics of contemporary trauma theory. Viewed from the perspective of Freudian trauma theory, the protagonist, Zhizha, suffers from traumatic neurosis and psychological loss of faith in idealism as the image of her father crashes down to depths of indignity and shame. The memory of the horrific experience haunts her in later life and she feels entangled by intrusive thoughts. She is deluded, experiences identity-loss and harrowing nightmares which make her life miserable. If studied from the angle of contemporary trauma theory, Zhizha is a typical trauma victim as the disgraceful incident becomes threat to her autonomy. About the victims of traumatic experience, Felman and Laub believe that they can never recover from it, she elaborates:

Trauma survivors live not with memories of the past, but with an event that could not and did not proceed through to its completion, has no ending, attained no closure, and therefore, as far as its survivors are concerned, continues into the present and is current in every respect. The survivor, indeed, is not truly in touch either with the core of his traumatic reality or with the fatedness of its reenactments, and thereby remains entrapped in both" $(1992,69)$.

Consequently, we intend to situate the trauma in Under the Tongue within a number of overlapping frames. Our work adapts notions from the influential works on trauma developed by Sigmund Freud, Cathy Caruth, Anne Whitehead, Judith Herman and Roger Luckhurst. We will situate these conceptual frames within the selected text.

\section{Background of the Study}

Zimbabwean Yvonne Vera grew up in Bulawayo, a colonial ghetto. In 1995 she went on to work on doctorate at York University in Toronto; returned to her home city to become Director of the National Gallery in Bulawayo. Vera's intellect earned her numerous national and international awards. Under the Tongue deals with a private and painful theme, incestuous rape, which is such a shameful reality that it is usually kept secret by the family members; but the mother of Zhizha takes a bold step of avenging her daughter by killing her husband. Stylistically Vera has rejected linear plot structure, conventional symbols and predictable dénouement to the narrative crisis. She appropriates the literary voice and metaphoric representations to the theme of the novel. Her work is fragmentary though: "each fragment contains a message, contains a story, but resists a tidy or forced conclusion" (Hemmings 2004, 237). 


\section{Discussion}

Under the Tongue (1996) is an emblematic representation of trauma. The lyrical language reflects the heavy subject of a wounded and distressed girl who is sexually assaulted by her own frustrated father. Trauma is persistent in the novel, not only in the character of the protagonist, a 10-year old child, but is also explicitly portrayed in her mother and in grandmother also who feels it three times greater as she feels the pain not only of her daughter and granddaughter but is also reminded of her own pain which she has tried to bury carefully under heavy rocks. All the three generations are traumatised: the grandmother at the hands of her husband, the mother also at the hands of her husband and Zhizha by her real father.

Trauma has badly affected Zhizha's mental health. Zhizha is fundamentally suffering from a disorder of memory, which is one of the major symptoms in people who experience trauma. She feels so terrified and surprised at the brutal action of her father that her mind gets completely dissociated. It refuses to register the wound because workings of awareness and cognitions are completely destroyed by the emotional shock. The deeply engraved traumatic past comes in bits and fragments. These traumatic memories refuse to become a part of the narrative memory, but become frozen in time and are perpetually re-experienced in painful, disassociated traumatic present. Zhizha is conscious of the fact that "memory has left the sky. It is night" (Vera 1996, 124). All good memories have left her thoughts, now she is left only with the darkness of the night. Later she says, "I hear voices filled with tears. Darkness trembles with the memory of the moon. It is night" (130). The "moon" which symbolically represents romantic love has been crushed by her father's unhealthy action. In her painful existence, she can offer no space to the "moon" as it will clash with the darkness of the night and drown amid voices filled with tears. It is alarming that memory awakens forgotten "voices". Her grandmother weeps but her tears carry both darkness and dream which shows that she will push herself and others to come out of the state of trauma. Darkness is accompanied by dream which carries the notion that these oppressed women are struggling hard to replace nightmares of their lives with dreams of better future. When the characters are marked by the memories of the painful event, it essentially alters their identities.

Trauma in its very nature is structured in repetition. The loss of memory that is associated with the experience of trauma, never actually takes place thus entrapping the victim for a long period of time. Memory, an abstract concept, becomes real and concrete in Under the Tongue. The confusion of Zhizha is similar to the disorientation of grandmother who was insulted and degraded by her husband and community for giving birth to a sick son. It is a repetition which 
they all are trying to escape. The phenomenon of repetition compulsion, an urge to continually return to the traumatic event, is emphasised by repetitive use of images, "My voice blinded. My voice wishing to escape. My voice pulled from its roots, dug from sleep. My voice falling. My voice empty and forgotten. My voice slips..." (123). The repetition of the word "voice" reinforces the fact that she has lost not only her power of speech but it has affected her agency too. Now she does not have the power to establish her identity. She infinitely repeats the personal pronoun "my" every time to suggest that it is her personal loss which has harmed her individuality. Vera wants her readers to identify Zhizha's unheard voice. Her unheard voice becomes indistinguishable as it grows "small" and "faint" (124) and ultimately engulfs all her self-confidence. The ambiguity of these lines reinforces the bottomless psychic breakdown being experienced by the suffering individual.

Patterned cycles of inner sorrow are seen in the external world. The images of tree, water, rock, rain and sky are associated to pain which are difficult to forget and hide. The enormity of pain is suggested through the incomprehensibility of the world. For Zhizha, the burden is too heavy for her shoulders as she questions, "How can we carry it on our shoulders?"(160). She compares her pain to swollen clouds which are heavy with water, but this water has "salt" (123) mixed in it. The tears carry the saltish taste of the sea, which has collected the sorrows of generations in its lap. The grandmother of Zhizha thinks that their present sorrow "is greater than all our yesterdays" (160). The use of personal pronoun "our" suggests that all women characters are suffering individuals unlike male members of the community who are comparatively free to run after butterflies like Muroyiwa or in guerilla war-fare to become heroes like Tonderayi. Though repetition is a pleasurable sensation as it has symmetry and balance of energy in it, but in the case of trauma patients it carries a destructive tendency. Repetition becomes destructive as it turns out to be regressive. Here Zhizha, being trauma victim though cannot speak, but narrates in her monologue the same ideas over and over as it might help her, with the support of mother and grandmother, to work through the experience of injury. This happens because as Caruth says in Trauma: Explorations in Memory that the event is not fully experienced at the moment, but it is repeatedly experienced afterwards.

Trauma's irreversible damage to psyche makes trauma an unsolvable problem of the unconscious for it is essentially contradictory in terms of experience and language. Repression, one of the responses to trauma, is obviously visible as Zhizha has become silent which is one form of repression. Her grandmother also guides her to forget uncomfortable thoughts to deal with the situation. One such suggestion is, "it is sometimes good to forget, to bury the heavy things of now, the things which cannot be remembered ... such things are for forgetting, for burying beneath the earth" (131). The grandmother advises that such cumbersome realities 
must be forgotten to come out of the disturbed state of mind. Zhizha is slow to forget, so slow that she might never forget the oppressive incident entirely. The narrative flows and stagnates which is complicated by Zhizha's desire to forget the past, but the memories of the past intrude her attempt to forget. Tension between remembering and forgetting increases as series of interior monologues interspersed with small sentences and spaces between clusters of words are presented to suggest the timelessness of pain being felt by Zhizha. Zhizha is trying to learn new language. The effort she is employing in learning new language is manifested in circular and convoluted style of writing with meaning hidden in the body parts. The metaphorical meanings of these words are constantly in a state of flux. Sometimes words move in circular form. The circles, coming from nowhere join to form a lofty spiral. Talking about her grandmother's voice which is "gathering darkness" (130), Zhizha uses adjectives like piercing, swallowed, tremulous, surging, tumbling, forgotten and departed (130). Normally the adjective "flow" is associated with speech but here the protagonist uses all such adjectives which are related to the abnormal situations of human life. They do not suggest a smooth flow of time and speech but they are related to strong and windy weather, enormous water current which cuts through everything that comes in its way leading to destruction at enormous level. Vera attempts to develop an innovative style that amalgamates poetry and prose with linguistic elements drawn from African oral tradition and general conventions of writing.

Involuntary flashbacks are flooding Zhizha's life. The novel opens in retrospect with the knowledge of the entire narrative and a reference to what might happen in future. She desperately wishes for the "morning" (133) to return to their lives but "an unspoken word has arrived ... The word cannot be forgotten. It has grown large roots among [them]. Branches sprout the ground where memory is watered with death. This ground is stone but something grows on it" (161-162). She wants to forget the word but finds it difficult to do so. These traumatic flashbacks are different from recollection as they are not reliable and inadequate. She has to relive and re-experience the traumatic episode which is making it difficult for her to concentrate and focus on the present. This is turning her restless and frustrated. She says, "A heaviness grows on my forehead pulling me away into a darkness so complete and I cry, my crying seems to come from my ears. The darkness is taking me away" (217). These flashbacks compel the victim, suffering from trauma, to re-negotiate and rediscover meanings in relationships who have betrayed her by breaking tacit promises. This does not mean that the whole world around her has become doubtful; instead the other people around her are helping her to come out of the traumatic situation. Later she appeals to season, harvest, rain, river, rock, sky and earth to be with her. She wants to enjoy harmonious existence with nature that has always been very kind to her. This use of flashback reveals both psychological 
and emotional states of Zhizha's experiences. It is as if she is descending deep into the depths of psychical and emotional wilderness which is watered by tears fallen from the eyes of the survivor. Converting this wilderness into a site of tranquility requires a lot of effort because "those who undergo trauma, it is not the moment of the event, but of the passing out of it that is traumatic; that survival itself, in other words, can be a crisis" (Caruth 1995, 9; emphasis in original). Paradoxically these flashbacks help the victim to fully imbibe the traumatic experience which will afterwards lead to improvement of the survivor.

Recurring intrusion of vivid nightmares and repetition compulsion experienced by Zhizha form an essential part of her life. She wishes for a peaceful and comfortable sleep but she suddenly wakes up after experiencing "an embrace, once more, of lightening, entering into my sleep" (123). The recurrence of nightmares is very high which are strengthening death drive within her, "I die in my sleep" (123). These persistent nightmares are associated with horrible memories. They recur because traumatic memories are not linear like narrative memories. They are disjointed and jerky in nature. When people are assaulted by someone whom they cannot physically escape; they shift their state of consciousness. The person becomes completely powerless and goes onto a "state of surrender" (Herman 1992, 42). Zhizha's nightmare describes mental state of a person suffering from trauma. Thinking about her father she says, "His whisper is heavier than night, than dream, than silence. He carries death in his arms, banishes morning" (Vera 1996, 124). Night is associated with dreams but her dreams are converted into nightmares as she associates them to silence. Then she compares his whisper to eternal silence which is death. She further emphasises that father has not only brought silence and death to her but multiplied her miseries by banishing light and hope from her life.

Caught between the haunting memories during day time, she has to confront nightmares during night time which makes her life dreadful. The traumatised effect results in disorientation and gradual psychic decline which are reflected in chronological shifts and temporal curls created by the writer. Kopf $(2005,250)$ says:

The impression of flowing on the spot that Zhizha's mental language creates is repeated in the circular structure of her mental narrative ... We leave her right in her remembrance of the incest, which she narrateswith one brief exception - in present, not in past time, just as if it is still happening, as if there is no end and no temporal progression from it. [emphasis in original] 
Through highly lyrical language, she paints the pain and trauma by merging thoughts and memories with images drawn from nature. Vera aestheticizes trauma by engaging images and sounds of beauty which let her knit her stories around visual and conceptual moments. The feel of trauma is accompanied by grace and beauty of language thus helping in deferring the brutality of traumatic moments. Action and dialogues are scanty but dense poetic prose is rich with metaphoric imagery and delicate simplicity. In unconventional fiction of Vera, images overlap and interact combining the rhythms of landscape with a collage of impressions made on the mind of the reader. The free floating words and images suggest a quest for meaning while cracks and irregularities in chronology reflect the painful state of mind of a person suffering from trauma that is confused and is struggling to make sense of her identity. The gaps and holes are excessively used to generate a sense of impossibility of understanding the painful narrative of the victim. The complexity of these images increases to suggest the depth of pain, "My cry is silence. My cry searches the river, wavers between bending reeds, finds father waiting and near ... the dream in my belonging. I cry in a voiceless tremble, my eyes parched with darkness" (126). Ogbazi thinks, "Vera abhors this loss of speech. She without equivocation condemns the state of being voiceless because for her, survival is in the mouth" $(2011,124)$. The situation is growing paradoxical as she is crying but no one can hear. It is as if her cry is lost amid wilderness. Her father has hurt her to such an extent that she has lost her identity. From wilderness she reaches to a desert where there is so much dryness and darkness that even the water of her eyes has dried. Her cry which was silent is reduced to just "voiceless tremble" because she has lost the ability to express her sorrow of such a chaotic suffering. She says:

I run deep into the water my legs thick and heavy. I run. I fall. I fall a great height. I fall and fall and my voice meets me in collapsing waves, of sleep. My head is heavy because I have swallowed the water. My head grows and grows into my eyes ... I run because my voice is no longer me and my eyes are so filled with water (142-143).

Trauma resists narrative representation, it devises its own narration. The speech patterns used by Zhizha reflect that the pre-determined and common patterns of speech fail to communicate her personal and incongruous experiences. She picks up images from nature and her body to convey that she has become immobile and frozen in past. Her different body parts are not working in unison; instead they have become alienated from each other. To convey her sorrows of violence, she finds herself in a state of dilemma to tell the story until the end of the novel. Meanwhile she struggles to "demonstrate" trauma by omitting, merging, repeating and fragmenting details of her experience. Vera makes the reader witness her trauma by seeing Zhizha's inability and failure to tell the perpetrations of violence. 
Herman vividly describes that chronically traumatised people who are victims of family violence are often passive or helpless. The people in their environment tend to perceive them apathetic, quiet or depressed when in fact they live through vivid and multilayered interior struggles $(1992,91)$.

Zhizha successfully takes the reader in a nebulous state where it is difficult to differentiate between imaginations from reality, dreams from nightmares, fixity from flow. It is a semi-conscious state, when the mind is unable to clarify the foggy confusions but at the same time there is a strong urge to rub away the haze. Zhizha repeatedly makes effort to make the narration flow but has to confront hindrances that incessantly interrupt the smooth transmission of her feelings to her close associate, the grandmother. The circular structure of her mental narrative repeatedly takes the reader back to the beginning. The reader is never given an impression that the incident has taken place in the past but one gets the feel that it is happening now and here. She desperately searches for a word which can make the incident just a remembrance but cannot find it. Zhizha is in a way piecing together the pieces of a puzzle, because being so young cannot understand why the father has been so brutal to her.

Sleeplessness is another symptom of a person who is lost and blinded by trauma. Sleep is a kind of an escape from the distorted realities of life towards wholeness, but in case of sexual abuse, the body which is a site of trauma, cannot be put aside. It is there as a corporeal reality with which one has to negotiate to develop new connections. The act of sexual abuse takes the shape of Muroyiwa's footsteps as she says, "Footsteps approach, find the wounded voice, more sideways, step over it, move quickly past" (172). He crushingly enters her sleep, "I have been burnt and destroyed and turned into ash but I have lived, even in my sleep" (165). This problem of sleeplessness is associated with hyperarousal which makes her anxious and fatigued at the same time as she thinks that it is her father who "has swallowed her sleep" (123) which makes her feel tired and exhausted all the time. This sleeplessness has resulted in unease. She can hear unheard sounds which make her "tremble till [her] trembling is quiet. I hate the quiet" (133). To revert back to a normal and healthy life, proper sleep is as essential as proper diet but unfortunately for her food smelled like soot gathered in the mouth something very toxic. So both life giving forces - food and sleep are no more helping her to sustain. She has to forget her personal pain and confusion to sustain and affirm survival.

Sleeplessness is experienced during night time but hallucinations are timeless. They signify that past has completely overwhelmed the consciousness. The intrusive hallucinations are rooted in the traumatic event and they do not let her carry on routine activities. They possess the psyche of Zhizha as she cannot erase 
the image of her father before her eyes, "I see father in the midst of my cry. I see father. Father ..." (124; ellipsis in original). Though he is no more there, Zhizha's mother has murdered him but the daughter can see him very vividly before her eyes, though "the darkness is very large" (136). She can neither sleep at night nor in "hot afternoon" (144) because she says, "My ears echo a rattling sound. I search the inside of my ear with my small finger. I hear lizards running across the roof" (144). Zhizha's repetition of possessive nouns underscores her feeling that the pain she is undergoing is very personal. No one else can hear jarring sounds and horrifying lizards because it is not a haunted house. She rubs the inside of her ears to make sure as if sound is coming from inside or outside. She is not only caught between haunting memories and silence but also between nightmares and hallucinations. These hallucinations are fluid and ever-changing imaginative images subject to revision. Stylistically Vera's poetic fiction is also reflection of hallucination as she repeats herself at (ir)regular intervals, focusing on sensuous details in incongruous language using amorphous plot. Vera makes the reader enter the traumatised mind of the victim to make him feel the pain of a hallucinated individual.

Zhizha is numbed as she discovers that her self-esteem is nowhere to be found; she is in a state of surrender. She has gone into a state of trance because she cannot register the horrific event. Those things which she is seeing around herself have lost their ordinary meaning. Words for her are not a mean of communication but they adopt strange connotations for her, "A word does not rot, she says. It is not a fruit that rots on the ground. A word does not rot unless it is buried in the mouth for too long. A word buried in the ground only grows roots" (175). She is seeing language in a completely new light. It is being associated to a fruit as she is using adjective "rot" but right in the next line she clarifies that it is not a fruit but a "word" which has to be spoken. She has become silent because of severe shock which she has recently received from her father. She wants to talk which might help in soothing her pain. She knows the importance of speech as silence will further aggravate her mental condition, as she says that if words are kept in mouth, they will start spreading themselves by growing roots. Though women are trained by African culture to remain silent and obedient to patriarchal structures of the society but now it is far too long that they have kept their words hidden in their mouths. Now it is time to voice the unspoken and hidden realities of life with courage and strength because silence produces "individuals without anchor, without horizon, colourless, stateless, rootless - a race of angels" (Fanon 1967, 170). 


\section{Conclusion}

The chronological shifts and the temporal swings are related to the central theme of trauma which is being borne by the women characters of Under the Tongue. Zhizha, being the youngest finds it most difficult to cope with the situation. The oscillation between the present and the past imitates the mental state of Zhizha who is unable to accept the fact that the incident took place in the past, now the perpetrator is no more alive, and she has to survive in this world amid series of loops and knots of memories. Mental anguish and bodily memories of the traumatic event are hard to erase, and this is reflected in constructed silences, gaps and blanks in the text to touch the primary site of pain. Vera has consistently used patterns of images like dryness, sterility, voicelessness, fragmented memory, silence and submission to symbolise Zhizha's state of shaky mind which is a result of her tragic experience. Talking about Vera, Weiss says that she is one of those women who "take action, against their limited position by engaging in a discursive, dismantling, subverting, partly ironic, and deconstructing confrontation with androcentric texts not only of written material, but also, in a broader sense, of socio-cultural constructs and of texts written on the body" $(2004,14-15)$. Thus Vera suggests that women can become story tellers of their own experiences and should re-claim their suppressed voices in a patriarchal society.

\section{References}

Caruth, C. 1995. Trauma: Explorations in memory. Baltimore: The Johns Hopkins University Press.

1996. Unclaimed experience. Baltimore: The Johns Hopkins University Press.

Fanon, F. 1967. The wretched of the earth. Harmondsworth: Penguin Books.

Felman, S. and Laub, D. 1992. Testimony: Crises of witnessing in literature, psychoanalysis, and history. New York: Taylor \& Francis.

Freud, S. 2015. Beyond the pleasure principle. New York: Dover Publications Inc.

Hemmings, J. 2004. "How all life is lived, in patches": Quilting metaphors in the fiction of Yvonne Vera. In The end of unheard narratives: Contemporary perspectives on southern African literatures, ed. B.Weiss, 235-250. Heidelberg, Germany: Kalliope Paperbacks.

Herman, J. 1992. Trauma and recovery: The aftermath of violence-From domestic abuse to political terror. New York: Basic Books.

Kopf, M. 2005. Writing sexual violence: Words and silences in Yvonne Vera's Under the Tongue. In Body, sexuality and gender: Versions and subversions in African literatures, eds. F. Veit-Wild and D. Naguschewski, 243-254. Amsterdam: Rodopi.

Luckhurst, R. 2008. The trauma question. London: Routledge.

Ogbazi, I.J. 2011. Speaking for the voiceless: Yvonne Vera's characters and social conditions. Journal of Arts and Humanities 12(2): 109-135. https://doi.org/10.4314/ ujah.v12i2.5 
Vera, Y. 1996. Without a name and Under the tongue. New York: Farar, Straus, and Giroux. Whitehead, A. 2004. Trauma fiction. Edinburgh, UK: Edinburgh University Press. https:// doi.org/10.3366/ edinburgh/9780748618576.001.0001

Wiess, B. 2004. Shades of utter(ing) silences in The Purple Violet of Oshaanto, Maru, and Under the Tongue. Journal of African Literature and Culture 4: 13-32. 